\title{
Correlation of serum antigen and antibody concentration with clinical features in HIV infection
}

\author{
Maadhava Ellaurie, Arye Rubinstein
}

\begin{abstract}
Serum antigen and antibody values were studied in 164 infants and children infected perinatally with HIV. HIV antigens p17, p24, gp41, and gp120 were determined in sera by immunoblot and antigen capture assays. Lymphocyte blast transformation, serum immunoglobulins, and circulating immune complexes were also evaluated. Altogether $\mathbf{5 0}$ patients had HIV antigens measured: $31(62 \%)$ patients had p17 antigen in the serum and 29 (58\%) had p24 antigen present. In 19 (38\%) and nine (18\%) patients, respectively, gp120 and gp41 were detected. All four HIV antigens were detected in seven (14\%) patients. There was a positive correlation between the concentration of each HIV antigen and clinical outcome. When sequential specimens were analysed, $120(73 \%)$ patients had p24 antigen present.

Patients with stage P2B and P2D (Centers for Disease Control classification) had the highest concentrations of p24 antigen with a mean of approximately $200 \mathrm{pg} / \mathrm{ml}$. Altogether $70 \%$ of patients with a p24 antigen concentration of $>30 \mathrm{pg} / \mathrm{ml}$ eventually died or had severe clinical disease within six to 24 months. Infants under 15 months of age with a p24 antigen concentration as low as $5 \mathrm{pg} / \mathrm{ml}$ also did poorly. Increased immunoglobulins and decreases in mitogenic responses and absolute CD4+ lymphocyte counts were more prevalent in patients with raised p24 antigen. Raised concentrations of circulating immune complexes were seen in the symptomatic phase of the disease whereas in the terminal stage of the disease raised serum antigen and a decrease in circulating immune complexes and absolute CD4+ lymphocyte count were evident. Loss of p24 and/or p17 antibody as well as a decreasing ELISA optical density for HIV antibody also signalled progression of the disease.
\end{abstract}

Albert Einstein
College of Medicine,
Department of
Pediatrics,
Bronx,
New York,
USA
Maadhava Ellaurie
Arye Rubinstein
Correspondence and requests
for reprints to:
Professor Maadhava Ellaurie,
310 Fullerton Avenue,
Newburgh,
New York 12550,
USA.
Accepted 8 August 1990

HIV is associated with clinical and immunological abnormalities. ${ }^{1-3}$ Previous studies in adults indicated that HIV antigenaemia was associated with progressive clinical disease. ${ }^{4-10}$ Asymptomatic adults with persistent HIV antigenaemia are at increased risk of developing AIDS or AIDS related complex. ${ }^{11}$ In the first few months of life the presence of HIV antigen is thought to be indicative of active disease as HIV antibody could be acquired passively from the mother. ${ }^{12}$ In addition, raised and persistent serum antigen concentrations occur in a subset of children with symptomatic HIV infection who do poorly (M Ellaurie et al, abstract presented at V International Conference on AIDS, Montreal, 1989). ${ }^{13-16}$

In the present study, we correlated HIV core and envelope antigenaemia with clinical and immunological abnormalities in a large cohort of HIV infected children.

\section{Patients and methods}

PATIENTS

One hundred and sixty two perinatally infected infants and children were studied at all stages of HIV infection classified according to the Centres for Disease Control (CDC), Atlanta, Georgia. ${ }^{17}$ Two additional patients were infected by transfusion of blood products. The ages of studied children ranged from 1 month to 11 years. The duration of follow up was six months to six years. Sequential determinations of serum antigen concentrations were obtained. In all patients HIV infection was confirmed by repeated serological tests, p24 antigenaemia, viral cultures and/or characteristic clinical symptoms.

Informed consent was obtained from the parents or guardians of the children studied. Human experimentation guidelines of the Albert Einstein College of Medicine were followed in the conduct of the clinical research.

\section{LABORATORY TESTS}

Serum immunoglobulins were determined by radial immunodiffusion (RID) using commercially available RID plates (Kallestad Labs).

Immunoblot assay for p17, gp41, and gp120 was done with nitrocellulose paper circles, $1 \mathrm{~cm}$ in diameter, that were washed in TRIS (trometamol) buffered saline (TBS), pH 7.5, dried, and placed individually into a 24 well culture plate (Gibco). Sera were absorbed onto the paper circles in two consecutive $2 \mu$ ladditions and allowed to dry. Unreacted sites on the paper circles were blocked with $3 \%$ gelatin in TBS followed by washing with TBS containing $0.05 \%$ Tween 20 . Mouse monoclonal antibodies against p17, gp41, and gp120 (DuPont Industries), diluted 1:5000 in TBS-1\% gelatin, were reacted overnight with dot blots in $250 \mu \mathrm{l}$ aliquots. After washing with TBS containing $0.05 \%$ Tween 20 , goat antimouse IgG conjugated to horseradish peroxidase (Biorad Labs) at 1:2500-1:5000 dilution was added. After two hours incubation, 1-chloronaphthol containing hydrogen peroxide was added. The colour reaction was read within half an hour and scored from negative to 4+according to colour intensity. 
HIV p24 antigen was measured by a commercially available solid phase antigen capture enzyme linked immunosorbent assay (ELISA) (DuPont). A total of 250 serum samples from 164 patients were evaluated.

Mononuclear leucocytes were isolated from heparinised whole peripheral blood by sedimentation over Ficoll-Hypaque. Blast transformation of patients' lymphocytes was quantitated after stimulation with concanavalin $A$, pokeweek mitogen, phytahaemagglutinin, and staphylococcus strain Cowan A as previously reported. CD4+ and CD8+ cells were quantitated by flow cytometry using an EPICS-C fluorescence activated cell sorter (Coulter Electronics) as previously reported.

HIV antibody was measured by a commercial ELISA and confirmed by western blot (Epitope).

CIQ assay for immune complexes-circulating immune complexes were measured by a commericial micro-ELISA procedure (Diamedix). Diluted serum specimens were added to goat CIQ coated wells. After incubation, the wells were washed and alkaline phosphatase conjugated antihuman IgG was added. After further washing the substrate p-nitrophenyl phosphate was added. The absorbance was read at $405 \mathrm{~nm}$ and results expressed as $\mu \mathrm{g} \mathrm{Eq} / \mathrm{ml}$. Normal values were $<20 \mu \mathrm{g} \mathrm{Eq} / \mathrm{ml}$.

Statistical analysis was performed by the Student's $t$ test.

\section{Results}

Fifty patients were evaluated by the immunoblot and antigen capture assays for the presence of the following HIV antigens: p17, p24, gp41, and gp120 (table 1). Thirty one of the 50

Table 1 Serum antigen and antibody values in 50 children infected with HIV

\begin{tabular}{lllll}
\hline & $p 17$ & $p 24$ & $g p 41$ & $g p 120$ \\
\hline $\begin{array}{l}\text { No (\%) of patients } \\
\text { positive for antigen }\end{array}$ & $31(62)$ & $29(58)$ & $9(18)$ & $19(38)$ \\
$\begin{array}{l}\text { No (\%) of patients } \\
\text { positive for antibody }\end{array}$ & $30(60)$ & $46(92)$ & $50(100)$ & $17(34)$ \\
$\begin{array}{c}\text { No (\%) of patients } \\
\text { positive for antigen } \\
\text { and antibody }\end{array}$ & $19(38)$ & $26(52)$ & $9(18)$ & $8(16)$ \\
\hline
\end{tabular}

Table 2 Antigens measured by immunoblotting in 50 patients

\begin{tabular}{lc}
\hline HIV antigen & No (\%) positive \\
\hline p17 & $31(62)$ \\
p24 & $29(58)$ \\
gp41 & $9(18)$ \\
gp120 & $19(38)$ \\
p17+p24 & $34(68)$ \\
gp41+gp120 & $20(40)$ \\
p17 or p24+gp41 or gp120 & $36(72)$ \\
p17+p24+gp41+gp120 & $7(14)$ \\
\hline
\end{tabular}

patients $(62 \%)$ demonstrated the presence of p17 antigen in the serum and $29(58 \%)$ had p 24 antigen detectable. In nine (18\%) gp41 was detected in the serum and gp120 was found in 19 (38\%). All four proteins (p17, p24, gp41, and gp120) were detected in seven of the 50 patients (14\%).

Three patients who were p24 antigen negative were p17 positive by immunoblotting. Thirty four of 50 patients (68\%) were p17 and p24 antigen positive and $36(72 \%)$ had at least one antigen present in their sera (table 2).

Utilising the antigen capture assay, p24 antigenaemia was detected in 120 of 164 patients (73\%) when sequential specimens were analysed.

In $60 \%$ of patients, pl7 antibody was detected and p24 antibody was found in $92 \%$ of patients. All patients initially had the gp41 antibody and gp120 was found in $34 \%$ of patients.

Ninety per cent of all patients were hypergammaglobulinaemic and $82 \%$ had decreased mitogenic responses. The absolute CD4+ lymphocyte count was $<600 / \times 10^{6}$ in $50 \%$ of patients. Circulating immune complexes were raised in 42 of $60(70 \%)$ patients with a mean (SD) of 62 (70) $\mu \mathrm{g} \mathrm{Eq} / \mathrm{ml}$. Patients with detectable serum antigen concentrations had higher serum immunoglobulin concentration compared with patients without detectable antigen (table 3). Decreases in mitogenic responses and absolute CD4+ lymphocyte counts were more prominent in patients with high serum antigen concentrations.

Three distinct phases of HIV infection were noted (figure). In the initial phase concentrations of circulating immune complexes were low and p24 antigen was undetectable or in low concentration. This phase was seen in most patients with CDC stage P2A. In the second or symptomatic phase concentrations of circulating immune complexes were high, p24 antigen was detectable, and the patients were symptomatic. Most of the patients in CDC stage P2B and P2C fell into this category. In the accelerated phase of the disease, the ELISA for HIV antibody frequently became negative, there was a loss of p24 antibody, and circulating immune complexes and CD4+ lymphocyte concentrations became very low and HIV antigenaemia increased before death. Not all patients go through all three phases. The accelerated phase usually followed the initial and symptomatic phases but could be seen in isolation under 1 year of age when patients developed opportunistic infection like Pneumocystis carinii pneumonia and died. In the latter case, raised HIV antigen and low circulating immune complex concentrations were observed.

The presence of HIV antigen in the serum preceded other immunological abnormalities

Table 3 Correlation of serum p24 antigen with immunoglobulins, mitogenic responses, and absolute CD4 + lymphocyte count

\begin{tabular}{|c|c|c|c|c|c|}
\hline & $\operatorname{Ig} G$ & $I g A$ & $I g M$ & $\begin{array}{l}\text { Depressed } \\
\text { mitogenic } \\
\text { responses }\end{array}$ & $\begin{array}{l}\text { Absolute } \\
\text { CD4+ lymphocyte } \\
\text { count }\end{array}$ \\
\hline $\begin{array}{l}\text { Serum antigen positive }(n=21) \\
\text { Serum antigen negative }(n=29) \\
\text { p Value }\end{array}$ & $\begin{array}{l}2480(740) \\
3306(380) \\
<0.05\end{array}$ & $\begin{array}{l}166(220) \\
433(383) \\
<0.05\end{array}$ & $\begin{array}{l}306(520) \\
665(540) \\
<0.05\end{array}$ & $\begin{array}{l}7 / 21(33 \%) \\
15 / 29(52 \%) \\
>0.05\end{array}$ & $\begin{array}{l}1816(1046) \\
326(206) \\
<0 \cdot 05\end{array}$ \\
\hline
\end{tabular}

Results are mean (SD). 


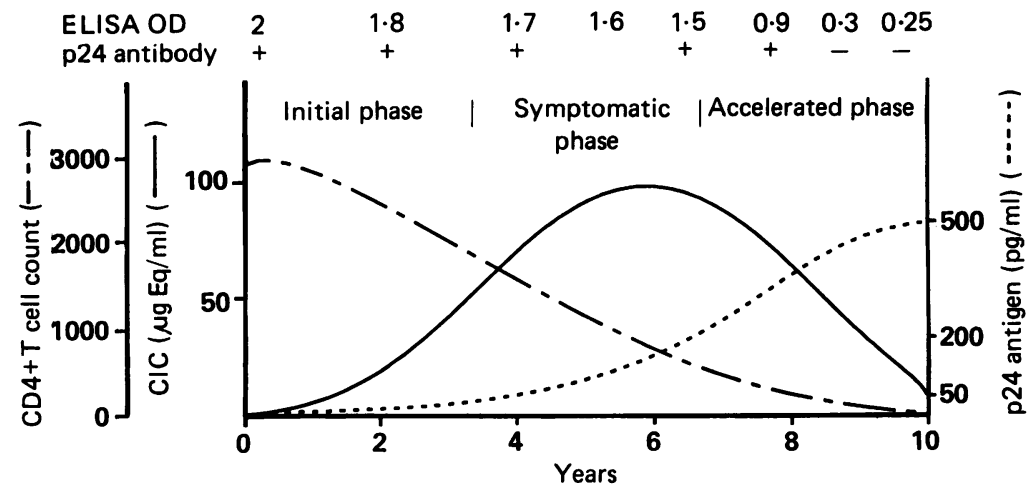

Circulating immune complexes (CIC) in $\mu \mathrm{g} E \mathrm{~g} / \mathrm{ml}, \mathrm{HIV}$ p24 antigen in $\mathrm{pg} / \mathrm{ml}$, absolute CD4+ lymphocytes, ELISA optical density (OD), and HIV p24 antibody are depicted for one patient. Three phases of the illness are apparent: initial phase with minimal or no symptoms and low CIC, low 244 antigen, and high CD4 $+T$ cells and ELISA OD; symptomatic phase with increased concentration of CIC, a rise of 24 antigen, and a decrease in $C D 4+T$ cells; and accelarated phase with a further rise in p24 antigen and decreased CIC, CD4 T T cells, ELISA OD and loss of p24 antibody before death.

like reversed T4:T8 ratio, hypergammaglobulinaemia, and depression of mitogenic responses in 20 patients and these patients had a poor outcome.

Thirty two of 42 patients $(76 \%)$ had detectable antigen under the age of 15 months. Twenty of these 32 patients died, 10 had progressive disease, and two had mild symptoms. Patients without or with low serum HIV antigens $(1+)$ had mild symptoms and were clinically stable for 24 months. Patients with high HIV antigen concentration (all four proteins $>2+$ ) had more severe clinical disease. The HIV antigen concentrations also increased significantly for months after the development of opportunistic infection. In six patients, viral infections like herpes and varicella also increased HIV p24 antigen with a decrease noted after the acute phase of the infection.

All patients who had greater than 3+ HIV antigen concentration (all four proteins) had opportunistic infertion, severe bacterial and viral infection, lymphoma, thrombocytopenia, and chronic pneumonitis. Ninety per cent of these patients died within six to 24 months.

In table 4, the serum p24 antigen is correlated with clinical staging according to the CDC. Thirty per cent of patients in the P2C category had a p24 antigen concentration $>100 \mathrm{pg} / \mathrm{ml}$ and did poorly. Patients in P2B and P2D stage had the highest mean (SD) concentrations of p24 antigen, $202(106) \mathrm{pg} / \mathrm{ml}$ and $204(224) \mathrm{pg} /$ $\mathrm{ml}$, respectively. Tests for p24 antigen were more frequently positive in stages $\mathrm{P} 2 \mathrm{~B}, \mathrm{C}, \mathrm{D}$, and $\mathrm{E}$ than in stages $\mathrm{P} 2 \mathrm{~A}$ or P2F.

Persistent antigenaemia was seen in 42

Table 4 Correlation of serum p24 antigen with disease stage according to CDC classification

\begin{tabular}{llcc}
\hline $\begin{array}{l}C D C \\
\text { stage }\end{array}$ & $\begin{array}{l}\text { No of } \\
\text { patients }\end{array}$ & $\begin{array}{l}p 24 \text { Antigen } \\
(p g / m l)^{*}\end{array}$ & $\begin{array}{l}\text { Log } p 24 \text { antigen } \\
(p g / m l)^{*}\end{array}$ \\
\hline P2A & 40 & $10 \cdot 9(2 \cdot 09)$ & $\cdot 58(0 \cdot 098)$ \\
P2B & 20 & $202(23 \cdot 7)$ & $2 \cdot 25(0.060)$ \\
P2C & 35 & $71 \cdot 2(16 \cdot 9)$ & $1 \cdot 42(0 \cdot 115)$ \\
P2D & 44 & $204(30 \cdot 8)$ & $2 \cdot 00(0 \cdot 087)$ \\
P2E & 5 & $27(4 \cdot 4)$ & $1 \cdot 40(0 \cdot 063)$ \\
P2F & 20 & $32(5 \cdot 1)$ & $1 \cdot 16(0 \cdot 161)$ \\
\hline
\end{tabular}

$\mathrm{p}$ Value was $<0.01$ for $\mathrm{P} 2 \mathrm{~B}, \mathrm{C}, \mathrm{D}$, and $\mathrm{E} v \mathrm{P} 2 \mathrm{~A}$; $\mathrm{p}$ value was $<0.001$ for P2C $v$ P2B+P2D

*Values are expressed as mean (SEM). patients and 15 patients had intermittent antigenaemia. Patients with intermittent antigenaemia had a milder disease course, but most of those with persistent antigenaemia had a poor outcome. Only three patients with progressive disease did not have detectable serum antigen. Seventy per cent of patients with p24 antigen concentrations of $>30 \mathrm{pg} / \mathrm{ml}$ eventually died or had severe disease within six to 12 months. Ten infants under 15 months with a p24 antigen concentration as low as $5 \mathrm{pg} / \mathrm{ml}$ did poorly.

Twenty of 50 patients (40\%) had loss of p24 and or p17 antibody and all these patients had progressive disease. Conversion from ELISA positive for HIV to ELISA negative and/or a decreasing ELISA optical density was seen in 15 patients and this signalled a progressive disease course.

\section{Discussion}

HIV antigenaemia has been previously associated with symptomatic disease. ${ }^{4-10}$ Severe clinical manifestations were found to be closely related to raised concentrations of HIV p24 antigen in adults. Adults with symptomatic HIV infection had p24 antigen detected more frequently in the serum than asymptomatic adults.

In the present study we evaluated the presence of four HIV gene products in the serum of HIV infected children. The most common gene product was p17 in $62 \%$ of patients, followed by p24 (58\%), gp120 (38\%), and gp41 (18\%). Three patients who were p24 antigen negative were p17 antigen positive. Using multiple antigens, the positive yield increased from $58 \%$ with p24 antigen alone to $72 \%$ utilising all four antigens. Thus an assay system detecting multiple antigens is potentially more useful than detecting p24 antigen alone. We also quantitated the HIV antigens by immunoblot and antigen capture assays and correlated them with disease course. The antibody profile of these patients was also examined.

By studying circulating immune complexes, CD4+ lymphocytes, HIV antigens, and HIV antibody by ELISA and western blot, three stages of HIV disease are apparent. They consist of an initial phase of absent or mild symptoms, a phase with symptoms, and an accelerated phase that precedes death. The results of laboratory tests depend on the stage at which the disease is studied.

In children in whom high concentrations of one or more HIV antigens were detectable in the serum, death followed within six to 24 months and was preceded by increasing HIV antigen concentration. Children who had low or undetectable serum HIV antigen remained stable or had mild symptoms (P2A). Seventy per cent of patients with a p24 antigen concentration $>30 \mathrm{pg} / \mathrm{ml}$ had a poor outcome. This is in contrast to a previous report in which higher concentrations of p24 antigen denoted a poor prognosis. ${ }^{15}$ This may be due to the greater sensitivity of the DuPont antigen capture assay. The reason why $30 \%$ of patients with p 24 antigen concentrations $>30 \mathrm{pg} / \mathrm{ml}$ did not do poorly could be due to upregulation of HIV gene 
expression by infection ${ }^{18}$ and tumour necrosis factor. ${ }^{19} \mathrm{~A}$ decreasing antibody concentration as determined by ELISA or loss of p24 and p17 antibody was also indicative of progressive disease as seen in adults. ${ }^{20}$ Thus monitoring of HIV antigen and antibody as well as concentrations of circulating immune complexes and CD4+ lymphocytes is of predictive value. Very high p24 antigen concentrations in isolation may not necessarily be predictive of a poor outcome as high values may be seen in association with other viral infections. Therefore, HIV infected children with a p24 antigen concentration $>30 \mathrm{pg} / \mathrm{ml}$ and poor immune function need to be monitored more closely and treated aggressively. Infants under 1 year with any detectable antigen should also be treated aggressively and given prophylaxis for $P$ carinii pneumonia. Other HIV antigens-p17, gp41, and $\mathrm{gp} 120$ - in addition to p24 are of independent predictive value.

This study was supported by a grant from the National Institutes of Health (AI20671).

1 Quinnan GV, Siegel JP, Epstein JS. Mechanisms of T cell functional deficiency in the acquired immunodeficiency syndrome. Ann Intern Med 1985;104:710-4.

2 Klatzman D, Barre-Sinoussi F, Nageyre MT. Selective tropism of lymphadenopathy associated virus for helper inducer T lymphocytes. Science 1984;225:59-63.

3 Fauci AS, Macher AM, Longo DL. Acquired immunodeficiency syndrome: epidemiologic, clinical, immunologic and therapeutic considerations. Ann Intern Med 1984;100: a6-106.

4 Wittek AE, Phelan MA, Well MA, et al. Detection of human immunodeficiency virus core protein in plasma by enzyme immunoassay. Association of antigenemia with symptomatic disease and T-helper cell depletion. Ann Intern Med matic disease and
5 Pederson C, Nulsen CM, Vestergoard BF, Serstoft J. Temporal relation of antigenaemia and loss of antibodies to core antigens to development of clinical disease in HIV infection. BMF 1987;295:567-69.

6 Lange JMA, Paul DA, Huisman HG. Persistent HIV antigenaemia and decline of HIV core antibodies associated with transition to AIDS. BMF 1986;293:1459-62.

7 Lange JMA, Goudsmit J. Decline of antibody reactivity to HIV core protein is secondary to increased production of HIV antigen. Lancet 1987;i:448.

8 Cao Y, Valentine F, Hojvat S. Detection of HIV antigen and specific antibodies to HIV core and envelope proteins in specific antibodies to HIV core and envelope proteins in

9 Lange JMA, Paul DA, de Wolf F. Viral gene expression, antibody patterns and immune complex formation in antibody patterns and immune complex forms 1987; human

10 Goudsmit J, de Wolf F, Paul DA. Expression of human immunodeficiency virus antigen (HIV-Ag) in serum and cerebrospinal fluid during acute and chronic infection. Lancet 1986;ii:177-80.

11 de Wolf F, Goudsmit J, Paul DA. Risk of AIDS-related complex and AIDS in homosexual men with persistent HIV antigenaemia. $B M \mathcal{F}$ 1987;295:513-6.

12 Blanche S, Le Deise F, Fischer A. Longitudinal study of 18 children with perinatal LAV/HTLV III infection: attempt at prognostic evaluation. 7 Pediatr 1986;109:965-70.

13 Epstein LG, Boucher CAB, Morrison SH. Persistent human immunodeficiency virus type I antigenemia in children correlates with disease progression. Pediatrics 1988;82: 919-24.

14 Borkowsky W, Krasinsky K, Paul D. Human immunodeficiency virus infections in infants negative for anti-HIV deficiency virus infections in infants negative for anti-HIV

15 Borkowsky W, Krasinsky K, Paul D. Human immunodeficiency virus type I antigenemia in children. $\mathcal{F}$ Pediatr deficiency virus

16 Ellaurie M, Calvelli T, Rubinstein A. Reduction of HIV Ellaurie $M$, Calvelli T, Rubinstein A. Reduction of HIV
antigens following intravenous gammaglobulin in pediatric HIV infection. Blood 1987;70:119a

17 Centers for Disease Control. Classification system for human immunodeficiency virus (HIV) infection in children under 13 years of age. MMWR 1987;36:225-36.

18 Mosca JD, Bednarik DP, Raj NBK, et al. Herpes simplex virus type-1 can reactivate transcription of latent human immunodeficiency virus. Nature 1987;325:67-70.

19 Okamoto T, Matsuyama T, Mori S, et al. Augmentation of HIV type-1 gene expression by tumor necrosis factor alpha. AIDS Research and Human Retroviruses 1989;5:131-8.

20 Lange JMA, de Wolf F, Krone WJA. Decline of antibody reactivity to outer viral core protein p17 is an earlier serological marker of disease progression in human immune deficiency virus infection than anti-p24 decline AIDS. AIDS 1987;1:155-9.

\section{Shigella seizures}

Authors should get their title right if nothing else. My eyes were drawn to a paper headed 'Recurrent seizures in children with Shigella-associated convulsions (Lahat et al, Annals of Neurology 1990;28:393-5). Strange, I thought, I didn't know that convulsions with shigellosis were likely to recur. Well the point of the paper is to show that they aren't!

Fifty five children were followed up for between seven and 14 years. None had afebrile seizures and two had febrile convulsions in that time. Convulsions with shigella infection are different and do not carry the recurrence risk of febrile convulsions in general.

This paper opens up limitless possibilities for intriguing titles: 'Acrocephalopolysyndactyly in Prader-Willi syndrome'-it doesn't happen or 'Ochronosis following valproate therapy'we've never seen it.

It could become a popular parlour game. 